\title{
La desocultación de América en el arte desde la perspectiva de Rodolfo Kusch *
}

The disclosure of America in art from the perspective of Rodolfo Kusch

Por: Castillo, Branco David*

Universidad Nacional de Jujuy.

San Salvador de Jujuy, Argentina

Correo electrónico: brancodavidcastillo@gmail.com

Fecha de recepción: 21/05/2021

Fecha de aprobación: 26/05/2021

DOI: $\underline{\text { http://dx.doi.org/10.30972/nvt.1715359 }}$

\section{Resumen}

El presente artículo pretende introducirnos en el pensamiento estético del filósofo latinoamericano Rodolfo Kusch, a partir de analizar el uso y la procedencia de categorías de pensamiento provenientes de la filosofía de Martín Heidegger tales como la verdad entendida en tanto desocultamiento y la manifestación de la misma en la obra de arte. A partir de esta posible línea de ingreso al pensamiento kuscheano, nos proponemos profundizar respecto de qué está diciendo Kusch cuando afirma que en el arte se confiesa la verdad de lo americano. En la segunda mitad del artículo, se busca desplegar una caracterización genérica del pensamiento kuscheano que visibilice la novedad del mismo más allá de la influencia heideggeriana; para ello realizaremos un recorrido específico por los textos y apartados de reflexión estética que aparecen en la obra del pensador argentino.

\footnotetext{
* Este trabajo se inscribe en el proyecto de investigación: "Reconocimiento y alteridad: El problema del otro en Latinoamérica" perteneciente a la UI Unidad de investigación Ciencias, culturas y procesos sociales en Latinoamérica de la Universidad Nacional de Jujuy.

* Profesor de filosofía (Escuela Normal $N^{\circ} 2$ de la ciudad de Rosario, Santa fe); Licenciado en filosofía (Universidad Nacional de Jujuy), Diplomado en Filosofía de la Liberación (Universidad Nacional de Jujuy).
} 


\section{Branco David Castillo}

Palabras clave: Desocultación - obra de arte - Geocultura - conjuro - América verdad.

\section{Abstract}

This article aims to introduce us to the aesthetic thought of the Latin American philosopher Rodolfo Kusch. To do this, it will be essential to understand the use and origin of categories of thought from Martin Heidegger's philosophy, such as truth understood as disclosure, and its manifestation in the work of art. Starting from this possible line of entry into Kuschean thought, we propose to delve into what Kusch is saying when he affirms that the truth of the American is confessed in art. In the second half of the article, we seek to display a generic characterization of Kuschean thought that makes its novelty visible beyond the Heideggerian influence; For this we will carry out a specific tour through the texts and sections of aesthetic reflection that appear in the work of the Argentine thinker.

Keywords: Disclosure - Artwork - Geoculture - Conjuring - America - Truth

\section{Cómo citar este artículo:}

APA: Castillo, B. D. (2021). La desocultación de América en el arte desde la perspectiva de Rodolfo Kusch. Nuevo Itinerario, 17 (1), 310-333. 
“¿Pero cómo acontece la verdad? Nuestra respuesta es que acontece en unos pocos modos esenciales. Uno de estos modos es el ser-obra de la obra." Martin Heidegger; El origen de la obra de

arte.

"Cuando Heidegger se refiere al cuadro de Van Gogh, hace notar que en el mismo se daba la totalidad, el sentido de vivir del aldeano a nivel obra. O lo que es lo mismo, sale a relucir la desnudez del ser aldeano, la verdad universal de ser aldeano"

\section{Introducción}

El presente trabajo nos introduce al pensamiento de Rodolfo Kusch desde la perspectiva estética. Una estética que, como veremos, se despliega en un sentido heideggeriano, y por ende en clave ontológica, ya que en la obra de arte se expresa, según Heidegger, el ser del ente. La tesis expuesta a continuación sostiene que en la obra de arte se da la posibilidad de sondear la verdad de lo americano tal como lo sostuvo el filósofo argentino Rodolfo Kusch. Ahora bien, para desandar esta idea será preciso esclarecer varios elementos que componen dicha idea.

En primer lugar, habrá que explicitar el concepto de verdad como desocultación tal como aparece en el $\S 44$ de El Ser y El Tiempo ${ }^{1}$ de Martin Heidegger. De allí nos desplazaremos hacia una conferencia posterior a El Ser y El Tiempo titulada como El origen de la obra de arte ${ }^{2}$. En ella nos encontraremos con que uno de los modos en que la verdad como desocultación se manifiesta y acontece es en la obra de arte. El despliegue de ese argumento será necesario para entender la recepción y la réplica que tendrá la desocultación en la filosofía de Rodolfo Kusch.

\footnotetext{
${ }^{1}$ Heidegger, M; (1951) El Ser y El Tiempo; México, Fondo de Cultura Económica.

${ }^{2}$ Heidegger, M; (1995) El origen de la obra de arte, en Caminos del bosque; (pp. 11-62) Barcelona, Alianza Editorial.

Nuevo Itinerario: Desafíos del pensamiento latinoamericano y decolonial 
Luego de aclarar ello, nos adentramos en la obra del pensador argentino. Las categorías principales de su pensar nos ocuparán en un primer momento abocado a la panorámica general de la filosofía de Rodolfo Kusch. El concepto de geocultura, la dualidad entre ser y estar y la prospectiva del estar-siendo, serán desarrollados a los fines de comprender con mayor lucidez el papel del arte en el seno de su filosofía.

Los últimos apartados serán, dedicados ahora sí, a la estética kuscheana. La importancia de la palabra poética para nombrar el ser de lo americano será el punto conductor que nos guiará en un recorrido por dos textos centrales del autor. En primer lugar, repasaremos los Apuntes $^{3}$ juveniles de Kusch en torno a una estética de lo americano, y, por último, se hará hincapié en un capítulo de Geocultura ${ }^{4}$ en el cual Kusch retoma el planteamiento estético como modo de desocultar la verdad de lo americano. La resonancia del poema del Martín Fierro ${ }^{5}$ entendido éste como un arte del conjuro, en línea con el pensar indígena y popular de América, aparece como la tesis más arriesgada de nuestro autor en la búsqueda de una poética que sea capaz de desocultar la verdad que América necesita confesar.

\section{La desocultación}

El Ser y El Tiempo de Martín Heidegger irrumpe en el mundo filosófico de comienzos del siglo XX con el planteamiento del olvido del ser y la recuperación de su pregunta fundamental. Allí aparecerá interrogado nuevamente el sentido del ser, pero esta vez, desde el horizonte de la temporalidad. El texto quedará inconcluso, en términos de Heidegger, "por insuficiencia del lenguaje todavía condicionado por la metafísica" (Vattimo 2002, p. 59). No obstante, deja delineado, al menos, las pautas generales para una destrucción de la metafísica tradicional ${ }^{6}$. Ese proyecto le sirve a

\footnotetext{
${ }^{3}$ Kusch, R; (2007) Anotaciones para una estética de lo americano, en Obras completas, Vol. IV, (pp. 779815) Rosario, Argentina. Editorial Fundación Ross.

${ }^{4}$ Kusch, R; (2007) Geocultura del hombre americano, en Obras completas, Vol. III, (pp. 8-239) Rosario, Argentina. Editorial Fundación Ross.

5 Hernández, J; (2005) Martín Fierro; Buenos Aires, Editorial Debolsillo.

${ }^{6}$ EI $\S 6$ de El Ser y El Tiempo afirma una destrucción de la historia de la ontología, que luego, en sus textos posteriores pasará a designarse como metafísica tradicional o metafísica de la presencia. 
Heidegger para revelar su tesis fundamental: al ser lo comprendemos siempre desde un horizonte temporal y, por ende, el sentido de éste cobra una delimitación epocal y una referencia a cada pueblo histórico que se pregunta por él.

Es en ese contexto de la obra en donde encontramos su concepto renovado de verdad como desocultación. En efecto, mucho antes de que la verdad se presente como una correspondencia entre el enunciado y la cosa referida, el horizonte de sentido, la comprensión del ser que los envuelve a ambos, tiene que estar descubierta y precisada. Por ello, la desocultación del ente en su ser, el develamiento de ese sentido profundo que sostiene al ente en cada época histórica, cobra una importancia de primer orden en relación con la adaequatio.

Es así que Heidegger resuelve el último parágrafo de la primera sección de El Ser y El Tiempo con una divisoria en torno a dos concepciones o niveles de la verdad como tal. La verdad como adecuación entre la proposición y la cosa es entendida como un derivado y deudor de la verdad como desocultación, cuya naturaleza se presenta en un nivel primigenio e inaugural en relación con la adaequatio.

\section{La pregunta por el arte en Heidegger}

Ahora bien, ¿dónde veo ese nuevo concepto de verdad?; ¿cómo compruebo esa originariedad de la desocultación según los planteos de El Ser y El Tiempo?

A estas preguntas contesta Heidegger con sus conferencias sobre la obra de arte. Dichas conferencias fueron dictadas en Friburgo en noviembre de 1935 y repetida en Zúrich en enero de 1936. No obstante, su publicación tendrá que esperar quince años más, hasta la aparición de Holzwege en 1950, libro que compila éste y otras conferencias y ensayos del autor escritos en la época posterior a El Ser y El Tiempo.

En ese texto, Heidegger se sirve de la experiencia del arte para expresar el modo y uno de los lenguajes fundamentales en los que la verdad como desocultación acontece. Como veremos a continuación, la pintura de Van Gogh y su revolucionaria gesta estética, le da pie a Heidegger para expresar de qué forma la verdad de una época se revela a un pueblo histórico en la obra de arte mucho antes que en las proposiciones de la ciencia positiva.

Nuevo Itinerario: Desafíos del pensamiento latinoamericano y decolonial 
En este sentido, la pregunta por la obra de $\operatorname{arte}^{7}$ en el pensamiento heideggeriano da un giro radical. Ya no pensamos al arte en forma a-teorética con propiedades meramente decorativas, ceñido a la vida sentimental de lo humano, en oposición al campo de la lógica y de la ciencia que se ocupan del conocimiento y de la verdad. Ahora, el arte se revela como uno de los lenguajes originarios en los que la verdad de una época se desoculta a un pueblo histórico, y este concepto será iluminador en la búsqueda que emprende Kusch, pocos años después, detrás del sentido profundo de lo americano.

\section{El origen de la obra de arte.}

El texto publicado en Holzwege en 1950 genera, según los comentaristas principales, una sensación filosófica en Europa de post guerra ${ }^{9}$. Y, a su vez, tal como nos proponemos demostrar en el presente artículo, gozará de una gran acogida en el pensamiento latinoamericano de Rodolfo Kusch.

Dicha conferencia se articula en cuatro apartados fundamentales que le darán coherencia al argumento: 1. La cosa y la obra. 2. La obra y la verdad. 3. La verdad y el arte. 4. El epílogo. En el primer apartado Heidegger se pregunta por la condición de "cosa" de la obra de arte, topándose con el arsenal categorial de la metafísica de la presencia. En el segundo apartado, ahora Heidegger propone una nueva conceptualización para pensar la obra y lo hace a través de los conceptos de mundo y de tierra, en cuya tensión dialéctica se erige la verdad. En el tercer apartado la esencia de la obra de arte se revela como poesía. Poesía no en sentido literario, sino como

\footnotetext{
${ }^{7}$ La pregunta filosófica por el arte posee una larga trayectoria dentro del pensamiento occidental. Desde los tiempos de la Antigua Grecia que la tradición occidental viene dando un lugar al arte y la belleza dentro de la reflexión. Sin embargo, tendremos que esperar a los modernos, más específicamente a la época de la ilustración para que la estética empiece a desempeñarse como una disciplina filosófica autónoma, aunque como divisoria y en una relación secundaria para con la gnoseología. La emergencia del romanticismo en pleno siglo XIX va a subvertir este orden de prioridades exaltando la importancia del arte y su vínculo con la verdad, cuyas ideas encontrarán todo su esplendor en la obra heideggeriana.

${ }^{8}$ El texto posee tres traducciones al castellano. La primera es la de Samuel Ramos en México, publicado en Arte y poesía en 1958 por Fondo de Cultura Económica. La segunda, es la de José Rovira Armengol en Buenos Aires, publicada en Sendas perdidas en 1960 por Losada. La tercera, y la que goza de mayor reconocimiento entre los especialistas, es la de Arturo Leyte y Helena Cortés de 1995 en Barcelona, publicada en Caminos de bosque por Editorial Alianza.

${ }^{9}$ Gadamer, H; (2002) Los caminos de Heidegger; (p. 98) Barcelona, Editorial Herder. 
lenguaje inaugural que nombra el acontecer de la verdad histórica. Por último, en el epílogo Heidegger termina de delinear su concepto de obra de arte como acontecer de la verdad, con el elemento constitutivo de la belleza, que imperceptiblemente, viene acompañando desde siempre el acontecer de la verdad. Veamos cómo se desarrolla el argumento.

\subsection{La cosa y la obra}

Comienza el autor su búsqueda en torno a la esencia de la obra de arte preguntando por el tipo de cosa que ésta es. Pero ¿qué es una cosa? Heidegger indica que podemos diferenciar entre la mera cosa (piedra) por un lado, el utensilio (martillo) por otro, y la obra (un cuadro) en tercer lugar. Sin embargo, la comprensión tradicional sobre el ente que ha predominado en occidente desde los antiguos se expresa como metafísica de la presencia. La misma con la que se ha topado en El Ser y El Tiempo, al retomar la pregunta por el sentido del ser. Por eso es que, superado este escollo, decide ahora correrse de ese enfoque y ensayar otro camino.

Intenta empezar por el utensilio, y arribar de esta forma, al carácter de obra de la obra de arte. Pensemos entonces, en el utensilio. Heidegger propone un par de botas de campesino, y postula como ejemplo gráfico para referirnos a ellas, al cuadro de Van Gogh.

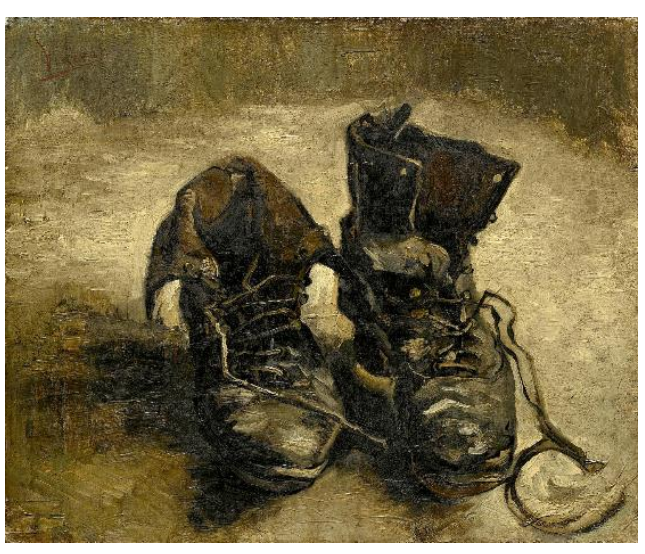
Claramente, dice Heidegger, "este tipo de utensilio sirve para calzar los pies" (p. 23). El cuadro muestra un par de botas y nada más. No nos dice quién los usa, dónde ni cuándo, y sin embargo...

“En la oscura boca del gastado interior del zapato está grabada la fatiga de los pasos de la faena. En la ruda y robusta pesadez de las botas ha quedado apresada la obstinación del lento avanzar a lo largo de los extendidos y monótonos surcos del campo mientras sopla un viento helado. En el cuero está estampada la humedad y el barro del suelo. Bajo las suelas 
se despliega toda la soledad del camino del campo cuando cae la tarde. En el zapato tiembla la callada llamada de la tierra, su silencioso regalo del trigo maduro, su enigmática renuncia de sí misma en el yermo barbecho del campo invernal. A través de este utensilio pasa todo el callado temor por tener seguro el pan, toda la silenciosa alegría por haber vuelto a vencer a la miseria, toda la angustia ante el nacimiento próximo y el escalofrío ante la amenaza de la muerte. Este utensilio pertenece a la tierra y su refugio es el mundo de la labradora" (Heidegger, 1995, pp. 23-24).

En la exégesis que hace Heidegger de la tela de Van Gogh, sale a relucir una dimensión profunda que ésta expresa. La relación afectiva del campesino con el utensilio, la comprensibilidad en la que éste se sostiene, el domicilio existencial que los vincula a ambos y el mundo en el que cobra sentido dicho útil se hacen presentes en el cuadro. De esa forma, sostiene Heidegger, la utilidad del utensilio retrocede ante el mundo en el que éste cobra valor y significado. La utilidad del útil, no es más que una consecuencia de esa comprensibilidad originaria. Aquella palpita en ésta, y no sería nada sin ella. Concluye así, que ha sido la obra de arte la que nos ha hecho saber lo que es de verdad un zapato. El cuadro de Van Gogh se presenta como aquella apertura por la que atisba la verdad del utensilio, del par de botas de labranza. Este sale a la luz como alétheia, como desocultamiento del ente en su ser. Por eso afirma Heidegger, que es en la obra de arte en donde se erige o se establece la verdad del ente, mucho antes que en la ciencia.

¿Pero no era que el arte se ocupaba de lo bello y que nada tenía que ver con la verdad? ¿No pertenece ésta al terreno de la lógica y la belleza al campo de la estética? Sin embargo, lejos de ocuparse aquí Heidegger de la verdad como adaequatio, cuyo lugar quedó en un plano secundario y derivado desde El Ser y El Tiempo, ahora nuestro pensador está buscando esa verdad primigenia y originaria entendida como desocultación, y en el arte va a encontrar uno de los modos en los que ésta se manifiesta. 


\subsection{La obra y la verdad}

Superando el escollo conceptual con el que se encontró en el primer apartado al preguntarse por la cosa de la obra, ahora Heidegger abandona la cosa para preguntarse por el ser-obra de la obra misma. ¿Cómo dar con el ser de la obra? Si nos remontamos a los museos, colecciones o exposiciones de arte, o bien si recurrimos a críticos o historiadores del arte nos encontramos que las obras están muy bien conservadas e interpretadas, pero que, sin embargo, las obras allí ya las encontramos convertidas en objetos. Objetos de la investigación científica u objetos del mercado. Difícilmente nos salga al encuentro allí el ser de la obra. Ya que estas obras han sido arrancadas fuera de su espacio esencial. "Las obras ya no son lo que fueron" (p. 29). De estas nos quedan solo objetos, pero esto ya no constituye la esencia de la obra. ¿Cuál será entonces el lugar propio de la obra?

Heidegger dice que el lugar de la obra es la verdad que acontece con ella. La obra abre su mundo con su acontecer desde la tierra. Mundo y tierra se convierten así, en los dos conceptos que Heidegger utiliza para mostrar ese ocultarse y desocultarse de la verdad que obra en el arte. ¿Qué significan aquí mundo y tierra? Mundo, dice Heidegger, es la apertura de lo ente, la morada en la que habita el hombre y todas las cosas que lo rodean. Y la tierra, es aquello en lo que reposa la obra misma. Es lo que hace emerger y da refugio. "Sobre la tierra y en ella, el hombre histórico funda su morada en el mundo. Levantar un mundo, y traer aquí la tierra son los dos rasgos esenciales del ser de la obra" (p. 34). Mundo y tierra difieren entre sí, pero son inescindibles uno del otro. Reposando sobre la tierra, aspira el mundo a permanecer por sobre ella, y ésta a su vez, tiende a enterrarlo permanentemente. Este es el combate, y en la intimidad de esa lucha, de ese juego, es en donde encuentra la obra su reposo.

¿Qué es la verdad entonces? Responde Heidegger diciendo que "la verdad es la esencia de lo verdadero" (p.36). Es decir, aquella apertura, aquel claro del ser, aquella precomprensión que torna verdadera tanto a la proposición como a la cosa, es lo que constituye la esencia de lo verdadero como tal. Sin embargo, este claro nunca es algo rígido y transparente, sino que su acontecimiento se manifiesta como un combate, 
como una lucha entre el mundo (desocultamiento) y la tierra (ocultamiento). Este se presenta como uno de los modos esenciales en los que se da la verdad. ¿Pero cómo tiene que ser la verdad para que ésta acontezca efectivamente en el arte?

\subsection{La verdad y el arte}

El interrogante con el que cierra el segundo apartado lo resuelve Heidegger en el siguiente. El arte, sostiene, es en su esencia un proyecto poético. Pero no la poesía como género literario, sino lo poético como lenguaje inaugural de una época histórica.

"La verdad como claro y encubrimiento de lo ente acontece desde el momento en que se poetiza. Todo arte es en su esencia poema, en tanto dejar acontecer la llegada de la verdad de lo ente como tal" (1995, p. 52).

La esencia de la obra de arte la encuentra finalmente en la poesía, y la obra se revela como uno de los modos esenciales de darse de la verdad. Está a su vez, puede acontecer, tanto en la obra, como en el estadista que funda un estado, en el sacrificio esencial del religioso, en el cuestionar del filósofo que piensa al ser, pero nunca en la ciencia, ya que frente a todos estos posibles...

"la ciencia no es ningún tipo de acontecimiento originario de la verdad, sino siempre la construcción de un ámbito de verdad ya abierto por medio de la fundamentación y la aprehensión de aquello que se muestra exacto dentro del círculo de un modo posible y necesario" (1995, p. 45).

En una inversión radical de lo que venía sosteniendo la modernidad, aquí Heidegger nos dice que la verdad originaria, lejos de darse en la proposición científica, esta se manifiesta en la precomprensión poética que funda el ámbito en el que la adecuación se hará posible de forma positiva.

Lo último que plantea, dentro de esta nueva conceptualización de la verdad, es que el arte, además de ser esencialmente poético, es también histórico por excelencia, ya que el arte funda historia. En cada puesta en obra de la verdad, todo lo que hasta entonces era tenido como habitual y normal, queda reducido a la nada. El proyecto poético que se erige infundadamente, se sirve del hombre y del resto de los entes para materializarse e inaugurar así, mundos históricos. 


\subsection{El epílogo}

Las páginas que conforman el epílogo de la conferencia dejan ver algunas conclusiones finales en torno a la tesis expuesta. La modernidad, había tomado al arte como objeto de la sensibilidad en sentido amplio, y no se había movido de ese lugar, desde entonces. Una época en la que "el gran arte", dice Heidegger, huyó del hombre. De esa forma, la verdad fue asociada al conocimiento científico, diferenciándola como objeto de estudio, tanto de la ética como de la estética. Sin embargo, la exposición de la verdad como desocultación en El Ser y El Tiempo, en relación originaria y primordial frente a la adaequatio intramundana, abrió el camino para una nueva conceptualización que permita mostrarla en su esencia. Esta conceptualización, la encontró Heidegger en la obra de arte, entendida ésta, como aquel proyecto poético que funda una época y sienta las bases fundamentales de la misma. Aquí, la belleza deja de aparecer al costado o a un lado de la verdad, y empieza a revelar su pertenencia esencial a la misma. Dentro de este nuevo y radical concepto de verdad, lo bello tiene su lugar, ya que imperceptiblemente, la belleza y la verdad han caminado juntas desde siempre.

El concepto de verdad que emana de la obra heideggeriana nos proporciona una verdad que lejos de entenderse como propiedad de ciertas cosas o ciertos enunciados, ésta se identifica con la desocultación del ser de los entes, con la manifestación del sentido epocal de las cosas en la palabra poética, que abre un mundo y funda la historia de un pueblo determinado.

\section{Rodolfo Kusch}

La filosofía americana de Gunter Rodolfo Kusch $^{10}$ no puede ocultar hoy la influencia insoslayable de la filosofía heideggeriana, sin que, por ello, su pensar pierda

\footnotetext{
${ }^{10}$ Nacido en Buenos Aires, de padres alemanes, Gunter Rodolfo Kusch (1922-1979) se formó como filósofo en la Universidad de Buenos Aires, obteniendo el título de profesor en filosofía el año 1948. Se desempeñó como técnico asesor para el Ministerio de Educación de la provincia de Buenos Aires durante sus primeros años de profesión y luego desplegó una larga trayectoria docente en Universidades argentinas y bolivianas. Sus pasos más destacados lo reconocen como un investigador profuso en el campo del pensar americano, al cual accedió no solo por medio una basta bibliografía personal que hoy
} 
originalidad. Sobradas son las investigaciones que hoy se despliegan en la línea que conecta el pensamiento de Martín Heidegger y la filosofía de Rodolfo Kusch ${ }^{11}$. No obstante, lejos de hacer un rastreo pormenorizado de esa influencia, el artículo viene siguiendo el hilo que conecta a Heidegger con Kusch, sobre todo en la utilización que hace nuestro pensador americano del concepto de verdad como desocultación y su manifestación en el arte. En efecto, si como vimos anteriormente, la obra de arte le sirve a Heidegger para mostrar la forma en que la verdad profunda de un pueblo histórico se revela a sus hombres, Kusch se va a hacer eco de esta idea y la aplicará en su búsqueda de un pensar americano propio. Ya que el discurso científico no le sirve a Kusch para penetrar en el ser americano, por su extrema carga de racionalismo, progresismo e industrialismo, es que nuestro filósofo apelará al arte como forma de desocultamiento de lo americano. Para ello, el rastreo de las principales categorías ontológicas de Kusch, su propuesta metodológica y sus alcances, nos servirán de preludio para entrar en el recorrido que nos proponemos hacer por cada resonancia que posee el arte en la obra de Rodolfo Kusch.

atestigua su casa de Maimará, sino que también inauguró la senda del trabajo de campo en el plano filosófico como método heterodoxo para conquista del saber. Sus últimos años los vivió en el pueblo jujeño de Maimará, allí donde descansan sus restos, desde entonces. Sus obras completas fueron editadas por la Fundación Ross entre los años 1998 y 2003. Desde entonces, las investigaciones académicas en torno a su figura y pensamiento no paran de crecer. Entre sus publicaciones encontramos tratados filosóficos como: La seducción de la barbarie (1953); América profunda (1962); Indios, porteños y dioses (1966); De la mala vida porteña (1966); El pensamiento indígena y popular en América (1971); La negación del pensamiento popular (1975); Geocultura del hombre americano (1976); Esbozo de una antropología filosófica americana (1978); Obras de teatro como: Cafetín (inédita); La muerte del chacho (1960); La leyenda de Juan Moreira (1960); y una infinidad de artículos en revistas y congresos, que aún hoy se siguen editando.

${ }^{11}$ Por citar algunos casos ejemplares; contamos con la tesis doctoral de Juan Cepeda H. en la Universidad Santo Tomás de Bogotá, Colombia, trabajo titulado como: La ontología de Rodolfo Kusch; Mandala ontológico de la filosofía latinoamericana, en 2017; artículos académicos como el de Graciela Maturo; (2012) La hermenéutica fenomenológica desde América publicado en el vol. 17, núm. 56, de la Revista Utopía y Praxis Latinoamericana de Venezuela; o ponencias como la de Diego Giani Vico, publicada en las actas publicadas de las Jornadas de Estudiantes del departamento de filosofía de la UBA en 2011, trabajo titulado como: Heidegger en Kusch. 


\section{Una ontología deformada}

Antes de arribar al pensamiento estético de Kusch, será necesario exponer algunas de sus principales categorías ontológicas que recorren la obra de nuestro pensador, para poder visualizar luego, con mayor precisión, el lugar y la función que posee el arte en su pensar.

\subsection{Geocultura del pensamiento}

En Kusch hablamos de una ontología deformada ${ }^{12}$ por el suelo. Tal y como lo había empezado a deformar el propio Heidegger, al ser lo comprendemos siempre desde una determinada temporalidad, y ahora con Kusch, desde una espacialidad también, específica. La geocultura aparece así en la obra madura de Kusch como aquel a priori existencial-geográfico que antecede toda intuición de lo absoluto, deformándolo.

"Es más, el concepto de unidad geocultural lleva incluso a cuestionar filosóficamente la posibilidad de un saber absoluto al modo como lo propone el pensamiento occidental (Kusch, 2003, pp. 254-255)"

Domicilio existencial, zona de habitualidad, o paisaje cultural, constituyen algunos de los sinónimos que se extienden en la obra de Kusch para hacer referencia a esta precomprensión geocultural. Una categoría que marca la intersección entre lo geográfico con lo cultural; la cultura leída como un modo peculiar de cultivo del contorno geográfico que se habita. La idea de un molde simbólico para la instalación de la vida y el intento de lograr un suelo que marque, a su vez, la gravidez con la que se gesta todo universal.

La cultura aquí ya no es leída como un objeto externo o un acervo propio del sujeto, sino como aquella circularidad simbólica que éste habita en el cruce con su geografía, y que se da casi de manera inconsciente.

\footnotetext{
${ }^{12}$ Ahumada, M; (2021) Sentipensar América; Anotaciones a partir de la filosofía de Rodolfo Kusch. (p. 37) Buenos Aires, Ediciones Ciccus.

Nuevo Itinerario: Desafíos del pensamiento latinoamericano y decolonial 


\subsection{La dualidad ser/estar}

La realidad americana es leída, a su vez, por Kusch, de forma dual. Los conceptos de ser y de estar propios de nuestro castellano representan, para nuestro filósofo argentino, dos dimensiones de la vida muy distintas entre sí, que atraviesan todas las culturas y al hombre en general, pero que él se va a encargar de mostrarlo bajo el ejemplo americano.

\section{El ser}

El verbo ser de nuestro castellano proviene del latín sedere cuyo significado se traduce como "estar sentado". El uso que dicho verbo ocupa en nuestra habla cotidiana se da siempre en relación con propiedades esenciales de las cosas, para indicar identidad o permanencia (Ej: el hombre es bueno; yo quiero ser alguien en el futuro). Intuye Kusch, a través de la etimología de la palabra ser y del uso que le damos entre nosotros, que ésta se utiliza para afirmar sustancialidad, esencia o presencia en el mundo, y que, por ende, se presenta como una categoría de nuestra mentalidad americana, ligada a la racionalidad occidental.

Esto último es importante, dice Kusch, ya que el término ser constituye también, el símbolo por excelencia de Occidente. El hombre, visto desde la Europa de Heidegger, es "el único ente sobre la tierra capaz de preguntarse por el sentido de todas las cosas: el ente ontológico." Y de allí, que todo balbuceo en torno al ser en la academia latinoamericana no sea más que la introducción colonial de un símbolo que representa lo europeo tanto dentro como fuera de su geografía.

En síntesis, bajo la categoría de ser, se refleja, entre nosotros, una forma de pensar en sintonía con la racionalidad científico-técnica, y una zona ontológica de América que expresa la vida ciudadana en las grandes urbes del continente, entendida por Kusch como el patio de los objetos ${ }^{13}$.

\footnotetext{
${ }^{13}$ El libro Il de América profunda lleva por título El patio de los objetos, una frase extraída por Kusch de Nicolai Hartmann, y que designa la ontología moderna, encarnada entre nosotros por el proyecto civilizatorio de los ilustrados porteños. Ver: Kusch, R; (2007) Obras completas Vol. II, (p. 131) Rosario, Argentina. Editorial Fundación Ross.
}

Nuevo Itinerario: Desafíos del pensamiento latinoamericano y decolonial. 


\section{El estar}

A diferencia de aquel, el verbo estar, que proviene del latín stare, cuyo significado expresa "estar parado", y su uso cotidiano refleja referencias a la inquietud, la ubicación, estado de ánimo, y contingencia. (Ej: "el hombre está triste; "su amigo está lejos"; "ella está trabajando"). La noción de estar constituye, en términos de Kusch, una referencia a la provisionalidad, al movimiento y a lo indeterminable. De allí que el estar se convierta en una categoría que exprese su diferencia ontológica respecto al ser, en tanto ésta revela una dimensión de la vida en la que lo humano encuentra sus límites frente a lo absoluto. Entiende Kusch, que el estar representa una convivencia con lo sagrado, por ende, una estancia en una zona indeterminada, y aunque devaluada por la modernidad, sin embargo, ésta constituye la antesala del ser, el suelo nutricio desde el cual un pueblo se define culturalmente.

Entre nosotros, el estar representa un modo de pensar todavía vivo en los sectores indígenas y populares, y una zona ontológica presente en el campo, en la selva y en los márgenes populares de las grandes ciudades americanas. El estar vivido, no como acción transformadora del mundo, sino como la primacía de lo divino. ${ }^{14}$

En síntesis, lo real se parcela, según Kusch, entre el ser y el estar como dos dimensiones de la vida, una expresada por la racionalidad objetivista, dominante en las ciudades occidentalizadas, y la otra como emocionalidad subjetivista, vivida a flor de piel por el indio en el campo como en las ciudades, conjugando así la ambigüedad ontológica que se da en América.

\subsection{Estar-siendo}

Estar sentado y estar parado constituyen, según Kusch, dos dimensiones ontológicas diferenciadas en América, pero confundidas y tensionadas entre sí desde los tiempos de la colonia. El ser, asociado con la vida ciudadana y con el proyecto civilizatorio de la ilustración, se pretendió instalar en América a partir de la supresión del estar, vinculado

\footnotetext{
${ }^{14}$ El libro I de América profunda lleva por título La ira divina, y explica, en una exégesis de las principales fuentes del mundo andino la cosmovisión o cosmoruray del mundo indígena y popular americano. Ver: Kusch, R; Obras completas. Vol. II (p. 23) Rosario, Argentina. Editorial Fundación Ross. 
éste, con la barbarie y lo popular. La propuesta kuscheana tenderá entonces, a desenredar este conflicto histórico a través de su fórmula resolutiva: el estar-siendo.

En efecto, desde los tiempos de la colonia, ya sea a través de evangelizaciones, conquistas internas, o sistema educativo, la construcción identitaria de las naciones americanas demandaron extirpar el vector mítico-emocional de nuestros pueblos para instalar la objetividad de los modernos europeos aquí en América. La fórmula fracasó una y otra vez, revelando su inautenticidad para lograr lo americano. Frente a ello, Kusch invierte la lógica, y propone su fórmula vegetal, intuyendo que la autenticidad cultural de las naciones, no se logrará transplantando un árbol ajeno sobre un suelo arrasado, sino cultivando el árbol propio que crece desde las profundidades de sus raíces y se alimenta de todos los nutrientes a su disposición, para dar el fruto esperado.

La propuesta del estar-siendo revierte el camino emprendido por los ilustrados porteños del siglo XIX. Ya no se trata de importar el ser para poder estar, en la clave del ser-estando. Si no, de partir de nuestro propio suelo, que implica asumir esas otras racionalidades que reinan en el fondo de américa, e integrarlas al vector ciudadano, para lograr una afirmación que contenga y exprese el mestizaje ontológico americano, bajo la clave del estar-siendo.

\section{La palabra poética}

En el prólogo del Esbozo para una antropología filosófica americana Kusch declara cuál es el sentido de su búsqueda ontológica. Sondear el fondo de América para retornar a lo pre-objetivo, a lo pre-óntico, abrir lo humano en su desnudez para poder encontrar desde allí, "nuestro verdadero modo de habitar esta América" (p. 250) bajo la sospecha de que allí anide nuestra privada y auténtica universalidad.

Pero su búsqueda sigue caminos sinuosos, senderos ambiguos y poco transitados, ya que el decir oficial a Kusch no le sirve. Afirma al respecto: 
"Hay palabras comunes y palabras grandes. La palabra común se dice para determinar, para decir esto es, o para señalar causas. Exige una verificación y para ello sirve la lógica aristotélica. Pero la palabra grande trasciende la palabra común, dice más de lo que expresa, porque abarca un área mayor. Para ella no hay lógica, en todo caso una meta-lógica, porque abarca también la verdad de la existencia, y, en tanto dice esto, no determina, sino que reitera lo mismo en todos los hablantes." (Kusch; 2003; p. 244)

La palabra grande no dice nada nuevo, sino que reitera, retrocede la mirada hacia donde ya estamos, y abre, de ese modo, la verdad de la existencia. Sigue Kusch:

"Es una palabra que se desempeña en el silencio. Dice lo que creemos saber o peor, lo que infructuosamente queremos saber: la palabra común termina en la ciencia, la palabra grande en la poética." (2003, p. 244)

En este sentido, ese decir que está buscando Kusch "no apunta a la palabra, sino a lo que se da antes, como quiere Heidegger, en la articulación del significado". (2003, p. 261) A ese horizonte simbólico de América, la precomprensión geocultural que nos envuelve, esa verdad profunda, que habrá de hallarse en la poética mucho antes que en la ciencia.

Una poética que en América se expresará como una poética de la compensación, del conjuro frente al hervidero espantoso que es el mundo, una poética que está buscando, según la lectura de Kusch, superar el caos por vía interior, ya en ritual, en la costumbre, en el canto, el arte, tratando de lograr ese centro simbólico que supere el desgarramiento, o que integre los opuestos.

\section{Anotaciones para una estética americana}

Las anotaciones de 1955 constituyen un ensayo temprano en la obra de Kusch, previo a América Profunda, pero que ya deja ver en su interior intuiciones expresas que se transformarán luego en algunas de sus categorías fundamentales. A su vez, el tema del texto gira en torno al problema del arte y al logro de una estética americana. La Nuevo Itinerario: Desafíos del pensamiento latinoamericano y decolonial 
referencia al arte como lenguaje de la desocultación es una constante que se reitera y se explicita a lo largo de este y otros textos que lo continúan.

Su planteo inicial, aparece en forma de interpelación. América necesita un arte de confesión. Necesitamos sacar a flote toda nuestra verdad, lo afirmado a nivel del ser y lo reprimido por el lado del estar demandan una liberación catártica que haga posible el llanto, que busque la reintegración, y nos otorgue el equilibrio nuevamente. Esa tarea le corresponde al arte, un arte del conjuro como llamará el propio Kusch.

\subsection{El punto de partida}

Comienza Kusch con una afirmación: "el arte americano es dual, es bifronte con dos caras. Detrás del formalismo elegante de Mitre la fealdad heroica del Martín Fierro" (2007, p. 779) Entre ambos, media una distancia abismal. Por un lado, el arte formal ciudadano de corte europeizado, que encarna una huida frente a lo americano. Se miente o se imita buscando un amparo no se sabe bien ante qué. Por el otro lado, un arte popular, que difícilmente entra en los recintos oficiales, un arte de analfabetos e iletrados, de experiencias estéticas más bien ligadas al fondo tradicional de américa. ¿Cómo interpretar esto?

\subsection{La estética de lo tenebroso}

El gran arte, sostiene Kusch, es aquel en el que la vida irrumpe contra el formalismo, aquel lenguaje que permite traer a la conciencia los instintos reprimidos para fagocitarlos, aquel movimiento en el que lo tenebroso asoma hacia la luz.

En nuestro caso, lo tenebroso que nunca emerge tiene que ver con lo americano en sus profundidades. Ya se trate del indio, del negro o del gaucho. Todas esas identidades conglomeradas en los sectores populares constituyen esa amalgama cultural históricamente reprimida en América que retumban constantemente en nuestra conciencia. Sin embargo, carecemos de un gran arte, una poética que nos 
ayude a traerlo a la luz. Para desanudar este camino, Kusch propone una lectura en clave histórica del problema americano y su vinculación esencial con el arte.

\subsection{El Espanto}

Comienza su recorrido con breves referencias al arte precolombino. La impresión inmediata del arte indígena en América, dice Kusch, es indudablemente el de la

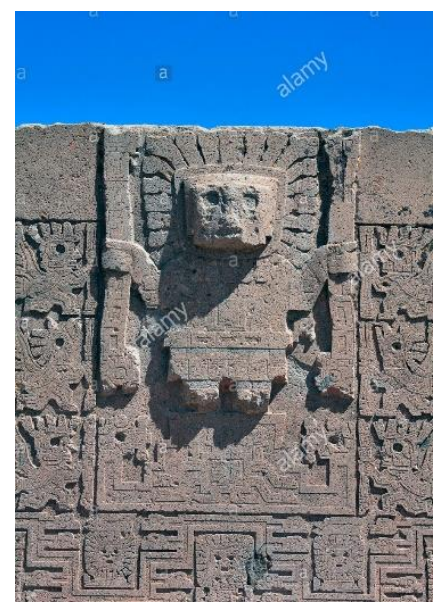
monstruosidad o el espanto. El mundo significaba para el indio Santa Cruz Pachacuti un "hervidero espantoso" (Kusch, 2007, p. 45) que era preciso conjurar, dominar, equilibrar, para lograr el fruto y garantizar la supervivencia. En esa contienda que se da al interior del mundo indígena entre lo humano y el espacio viviente, se despliega el vivir en América. Allí entreverá Kusch que anida el sentido de ese arte monstruoso de los indígenas.

Esta monstruosidad se vincula con la experiencia vital de la américa precolombina. La cultura indígena, dice Kusch, es una cultura estática de meseta que ha desarrollado la agricultura como modo de subsistencia, y, por lo tanto, su arte es una expresión de ese dominio geográfico de lo americano. Muy lejos se ubica éste del arte moderno europeo. Aquel un arte del hombre de llanuras, autocentrado en el sujeto que se autoretrata a sí mismo y a su mundo como un espacio vacío, objeto de su propia representación. En cambio, el arte indígena apunta hacia un mundo que tiene total primacía frente a lo humano. La figura central de la puerta de Tiahuanaco, o en el arte de paracas, aparecen referencias expresas a las fuerzas no humanas que dirigen el mundo. Las deidades del orden, pero también las del desorden y la desgracia.

"En otras palabras, el arte indígena surge del espanto humano ante el espacio inhumano, como cristalización sangrienta y tremenda de ese constante estar al borde de la muerte y de la aniquilación" (Kusch, 1955, p. 793)

En ese sentido, el significado dramático del arte indígena, se explica por la conexión que éste instaura con su vida misma. Un arte que surge de ese 
enfrentamiento de lo humano con el mundo en tanto hervidero espantoso. Un arte que apunta al equilibrio, y que, por ende, se presenta más bien como una conjuración del mundo antes que como expresión, y que constituye el antecedente vivencial del arte americano.

\subsection{La conquista}

Sin embargo, la conquista irrumpe en el arte americano sometiendo a un reemplazo del arte mágico-defensivo por un arte ofensivo-neutro más propio de la cultura europea. El mundo mágico plagado de dioses es reemplazado ahora por un mundo técnicamente dominable. Oficialmente esto se fue aceptando, aunque en el terreno social y político muchas veces emerge lo contrario. Dice Kusch:

"En América, lo vital yace a extramuros, en el suburbio o en el interior, donde la presencia del indio o del mestizo le agrega una dimensión telúrica difícilmente asimilable por la formalidad ciudadana." (Kusch, 1955, p. 803)

Esa vitalidad de lo americano, ese núcleo seminal de su geocultura no obstante, encontrará la palabra que lo haga emerger.

\subsection{El Martín Fierro}

Con el Martín Fierro, dice Kusch, ocurre algo especial. Probablemente el texto responda a la formación de lo gauchesco como ámbito literario que se estaba dando al margen de la literatura oficial del país, y esto pueda ser leído en clave política. Sin embargo, lo esencial del texto afirma Kusch se encuentra en sus personajes secundarios. En la aparición del negro, del indio, del gaucho, en suma. Lo real en el fondo del poema se expresa en esa estructura vital de lo gaucho como un estar arrojado a una espacialidad hostil y espantosa que éste tendrá que conjurar. Algo del significado profundo del arte indígena se deja ver en el poema de Hernández. En ese sentido, afirma Kusch, que "la salud de nuestro arte está del lado del Martin Fierro, del Juan Moreira o del Tango, o sea del subsuelo social de América" (Kusch, p. 812). Lo interpelante en América es el espacio, se lo perciba a este como llanura, como selva o 
como montaña. La vida expresada como un estar en medio del espanto de tener que enfrentar fuerzas destructoras ya sea en la naturaleza o en la política.

\section{Geocultura del hombre americano}

En Geocultura, texto de madurez, vuelve Kusch sobre la desocultación de lo americano a través del arte. En el capítulo dedicado a la cultura como entidad ${ }^{15}$ retoma su análisis del arte y sus referencias al Martín Fierro.

"Cultura, supone un suelo en el que obligadamente se habita" (p. 171). Esta comprende aquel horizonte simbólico que estructura y orienta el existir. En ese sentido, el sujeto cultural lo constituye, en primer orden, la geocultura, que es la que crea sentido, y luego el sujeto biográfico como artista. José Hernández es un simple gestor del poema. No interesa aquí el individuo llamado Hernández que escribe un libro llamado Martin Fierro. Ambos solo hacen referencia a las circunstancias de un fenómeno cultural. Ya que esta desocultación está por encima de autores y de libros, del artista y su obra.

"El sentido de la obra no se agota con el autor sino con el pueblo que la absorbe. Autor y obra son las dos dimensiones que más se analizan, pero el sentido que tiene una cultura se da en una tercera dimensión del fenómeno literario. El pueblo como tercera dimensión es el que agota el fenómeno cultural" (Kusch, 2007, p. 173)

Esta tercera dimensión marca la esencia de la obra de arte. Ese mundo, esa precomprensión geocultural que aflora en la obra, constituye el sentido profundo del arte como lenguaje de la desocultación.

Es probable que el gaucho haya ido a la pulpería y junto con la yerba y el azúcar compraba el poema de Hernández, no por afinidad política, ni siquiera por lo que el

\footnotetext{
${ }^{15}$ Kusch, R; (2007) La cultura como entidad; en Obras completas; Vol. III (pp. 170-180) Rosario, Argentina. Editorial Fundación Ross. 


\section{$\underline{1}$}

Branco David Castillo

autor haya querido lograr con su texto, sino por lo que el poema le decía algo al gaucho. Porque algún matiz de su mundo vital asomaba en él, y esa receptividad popular que gozaba el texto lo consagró finalmente como obra artística.

Esta es la perspectiva de la estética operatoria que Kusch está aplicando. Esa que entiende que al autor de una obra como un ente que se entona con una totalidad que lo inspira. La geocultura alienta la llegada de la obra, ésta se sirve del artista y de la materialidad de las cosas intramundanas para dejar acaecer su verdad profunda. Asienta Kusch: "el creador no es más que un vehículo de una totalidad que exige su cristalización o puesta en obra" (Kusch, 2007, p. 178).

En este aspecto, el arte, tal como habíamos visto en las Anotaciones para una estética americana, aparece siempre comprendido como desocultación de esa precomprensión geocultural. En nuestro caso, como desocultación de lo americano. Una traducción de ese mundo vital, y en esto insiste Kusch de manera constante, que se da en el arte mucho antes que en la ciencia.

\section{Conclusiones}

El texto buscó mostrar de qué forma la verdad de lo americano es desocultada en el arte. En un primer momento, analizamos el concepto de desocultación, que emana de la obra principalísima de Martín Heidegger, hablamos de El Ser y El Tiempo. Luego desplegamos una de sus posibles manifestaciones en el arte analizando el argumento que recorre su conferencia en torno al Origen de la obra de arte. De allí extrajimos una idea clara que será fundamental a la hora de entender la propuesta estética kuscheana: El arte es uno de los lenguajes en los que la verdad profunda de una época se manifiesta.

Luego de esclarecer el concepto de desocultamiento en el arte, el texto penetra en la filosofía de Rodolfo Kusch. Sus categorías fundamentales fueron el punto de entrada que nos diera la mayor perspectiva para enfocar luego, con claridad, el tema en 
cuestión. La premisa geocultural, la dualidad del ser y del estar, y la síntesis prospectiva del estar-siendo, constituyeron las categorías nodales del autor que el texto fue explicitando. Desde ese enfoque arribamos a la cuestión estética. Allí vimos como la palabra poética, palabra grande, que muchas veces habla silenciosamente, dice más que la palabra común que culmina en la ciencia. El arte revela esa dimensión existencial, emocional, preconceptual de la vida humana, buscando la catarsis, la expiación, en suma, la liberación psíquica-espiritual de un pueblo determinado.

Con breves referencias a una posible historia de la estética americana Kusch nos va mostrando como, en la América precolombina, el arte tuvo este significado confesional, de conjuro mágico frente al hervidero espantoso, pero que a partir de la conquista europea, el camino del arte se bifurca en dos caminos que se excluyen. Quizás el ejemplo recurrente del Martín Fierro sea, para Kusch, aquella obra que manifiesta con mayor claridad la implosión de ese mundo subyugado en la poesía gauchesca del siglo XIX y su propuesta resolutiva en la forma del conjuro, lo que más se aproxime a esa idea del desocultamiento que se da en el arte. Sin embargo, la problemática queda abierta en su obra, apenas señalada. Será cuestión de seguir esos caminos abiertos en el pensar de Kusch y seguir visualizando esos modos en los que la verdad de fondo asoma para nosotros en la forma en que nuestro pensador está reclamando.

Kusch nos demanda un arte de confesión, que despliegue toda nuestra verdad. Un arte que, revinculándose con la geografía, pueda expresar la verdad profunda de nuestra geocultura, y lanzar de ese modo, un conjuro hacia el horror y el espanto que tiñe América desde tiempos de la conquista. 


\section{Branco David Castillo}

\section{Bibliografía:}

Ahumada, M; (2021) Sentipensar América. Anotaciones a partir de la filosofía de Rodolfo Kusch. Ediciones Ciccus. Buenos Aires.

Cepeda Juan; (2017) La ontología de Rodolfo Kusch. El mandala ontológico de la filosofía latinoamericana. Bogotá, Universidad de Santo Tomás.

Gádamer, Hans Georg; (2002) Los caminos de Heidegger; (A, Ackermann, Trad.) Editorial Herder. Barcelona.

Givonne, Sergio; (1990) Historia de la estética; (M, García Lozano, Trad.) Editorial Tecnos. Madrid.

Heidegger, Martin; (1951) El Ser y El Tiempo; (J, Gaos, Trad.) FCE. México.

Heidegger, Martin; (1995) Caminos de bosque; (H, Cortés y A, Leyte, Trad.) Editorial Alianza. Madrid.

Hernández, J; (2005) Martín Fierro, Buenos Aires, Editorial Debolsillo.

Kusch, R; (2007) Obras Completas. Vol. I-IV; Editorial Fundación Ross, Rosario.

Picotti, D; (2010) Heidegger, una introducción; Editorial Quadrata. Buenos Aires.

Váttimo, Gianni; (2002) Introducción a Heidegger; (A, Báez,Trad.) Gedisa. Barcelona.

Villoro, L; (S/A) Verdad; en Enciclopedia Iberoamericana de Filosofía, Vol. 20. Editorial Trotta. 